\title{
Critical ischaemia of the lower limb: femorodistal bypass in preference to amputation
}

\author{
R D Sayers, M M Thompson, N J M London, P R F Bell
}

Conventional arteriography may miss patent calf vessels in patients with ischaemia of the lower limb

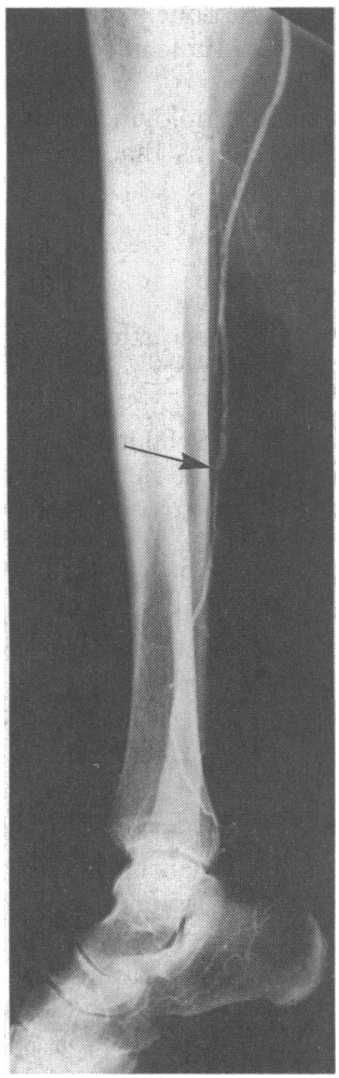

Arteriogram showing the vein graft anastomosed (arrow) to the peroneal artery in mid-calf

Department of Surgery, Clinical Sciences Building, Leicester Royal Infirmary, Leicester LE2 7LX R D Sayers, FRCs, lecturer in surgery

M M Thompson, MB, research fellow in surgery

N J M London, FRCS, lecturer in surgery

P R F Bell, FRCs, professor of surgery

Correspondence to:

Mr Sayers.
Critical ischaemia of the lower limb secondary to occlusion of the superficial femoral artery requires urgent revascularisation in order to avoid the need for amputation. ${ }^{1}$ If the block extends into the popliteal artery or its branches a femorodistal bypass to a calf vessel is the preferred procedure. ${ }^{2}$ The most important prerequisite for performing a femorodistal bypass is the presence of a calf vessel on which to site the distal anastomosis. Unfortunately conventional preoperative arteriography often fails to show the distal vessels, ${ }^{3}$ and may give the false impression that revascularisation is technically impossible. When this occurs the patient may not be referred for consideration of revascularisation and thus loses the chance of an attempt at saving the limb.

Several specialised vascular techniques, including Doppler ultrasonography and pulse generated run off (PGR), may allow identification of patent calf vessels before surgery. ${ }^{4}$ After these examinations surgical exploration of the calf vessels combined with intraoperative arteriography usually confirms the vessels' patency and femorodistal bypass can then be performed.

Although these techniques have been available for some time, it is important for non-vascular specialists to be aware of them. We have recently managed two cases and report them here to illustrate these points.

\section{Case reports}

CASE 1

A 77 year old non-diabetic woman was admitted to a local district general hospital with a two week history of rest pain in her right foot and an infected ischaemic ulcer over her right ankle. She had previously had intermittent claudication in her right calf for two years. Examination of her legs showed both femoral pulses to be present but no pulses were palpable below these on either side. She had three ischaemic ulcers around the right lateral malleolus with surrounding erythema and cellulitis.

A femoral arteriogram showed an occlusion of the right femoropopliteal segment and no patent distal vessels. Revascularisation was considered to be impossible and she was offered primary amputation to relieve her rest pain, which she refused. She was therefore referred to us for a vascular opinion. Auscultation at the ankle with a Doppler probe showed a patent peroneal artery which supplied an incomplete foot arch, and these findings were confirmed by pulse generated run off. She underwent exploration of the peroneal artery under general anaesthesia with a view to performing a femorodistal bypass procedure. An intraoperative arteriogram confirmed the patency of the peroneal artery from midcalf into the foot. A femoroperoneal bypass operation was performed with the in situ saphenous vein (figure). After the operation her rest pain resolved and her ulcers healed over the next four weeks. She remained well with a nonischaemic limb 18 months later.

\section{CASE 2}

An 80 year old non-diabetic woman was admitted to a local district general hospital with a 10 day history of rest pain in her left foot and a gangrenous toe. Examination of her legs showed both femoral pulses to be present but no pulses were palpable below these on either side. Her left foot was ischaemic with a positive Buerger's sign and a gangrenous third toe.

A femoral arteriogram showed an occlusion of the distal superficial femoral artery which extended into the popliteal artery and proximal calf vessels. The only distal vessel seen was a short segment of peroneal artery, which did not extend into the foot. Although revascularisation was considered to be impossible, she was referred for a specialist opinion.

Auscultation at the ankle with a Doppler probe revealed a patent peroneal artery, which was confirmed by pulse generated run off. Her peroneal artery was explored under general anaesthesia with a view to performing a femorodistal bypass. An intraoperative arteriogram was performed through the peroneal artery in mid-calf, which confirmed the artery's patency and showed that it supplied the distal end of the posterior tibial artery by a collateral at ankle level. A femoroperoneal bypass operation was performed, from the superficial femoral artery in mid-thigh to the peroneal artery in mid-calf, with the in situ saphenous vein. Her rest pain resolved after the operation and she had her gangrenous second and third toes amputated as a secondary procedure a week later. She was followed up in our vein graft surveillance clinic and remained well with a viable limb 18 months later.

\section{Discussion}

Patients with ischaemic limbs may be admitted under the care of doctors from various specialties including general physicians, diabetologists, geriatricians, and non-vascular general surgeons. An arteriogram is often performed to delineate the site and extent of the disease. If the superficial femoral artery is occluded and the block extends into the popliteal artery and its branches the arteriogram often fails to show patent calf vessels. A non-vascular specialist may then consider reconstruction to be impossible and the patient is denied the chance of surgery to save the limb.

Doctors should be aware that techniques such as Doppler ultrasonography and pulse generated run off can identify patent vessels when arteriography has failed to do so. Patients should be referred for an opinion from a vascular surgeon and if necessary to a specialist centre, so that their suitability for distal reconstruction can be assessed. They should not be denied surgery to save the limb on the basis of findings on conventional arteriography.

\footnotetext{
Bell PRF, Charlesworth D, DePalma RG, Eastcott HHG, Elkclöf B, Gruss JD, et al. The definition of critical ischaemia of a limb. Br f Surg 1982;69:S2. Bell PRF. Are distal vascular procedures worthwhile? Br $\mathcal{Y}$ Surg 1985;72:335.

3 Beard JD, Scott DJA, Evans JM, Skidmore R, Horrocks M. Pulse-generated run-off: a new method of determining calf vessel patency. Br f Surg

4 Scott DJA, Vowden P, Beard JD, Horrocks M. Non-invasive estimation of peripheral resistance using pulse-generated run-off before femorodistal bypass. Brf $\mathcal{F}$ Surg 1990;77:391-5.
}

(Accepted 4 September 1991) 